NBER WORKING PAPER SERIES

RATIONAL EXPECTATIONS AND THE

FOREIGN EXCHANGE MARKET

Peter R. Hartley

Working Paper No. $\underline{863}$

NATIONAL BUREAU OF ECONOMIC RESEARCH

1050 Massachusetts Avenue

Cambridge MA 02138

February 1982

This paper was prepared for the National Bureau of Economic Research's Conference on Exchange Rates and International Macroeconomics, held in Cambridge, Massachusetts, on November 21-22, 1981. This conference was organized by Jacob Frenkel and supported by the National Science Foundation. The research reported here is part of the NBER's research program in Intermational studies. Any opinions expressed are those of the author and not those of the National Bureau of Economic Research. 
Rational Expectations and the Foreign Exchange Market

\section{Abstract}

Many models of exchange rate determination imply that movements in money supplies and demands should result in movements in exchange rates. Hence, if rational agents are attempting to forecast exchange rate movements, they should in the first instance forecast movements in the supplies of and demands for money balances. Furthermore, if these underlying variables follow some stable autoregressive processes agents should use those processes to make their forecasts. If we identify the forward rate with the market's expectation for the future spot rate, rationality of expectations will imply testable cross-equation restrictions in a joint model of the autoregressions and exchange rate forecasting equation. This strategy is implemented in the paper using data on the $\mathrm{E} U \mathrm{UK} / \$ U S$ and DM/\$US exchange rates from the recent floating rate period.

Peter Hartley Princeton University and National Bureau of Economic Research

Economics Department Princeton University Princeton, NJ 08544

(609) 452-4032 


\title{
RATIONAL EXPECTATIONS AND THE FOREIGN EXCHANGE MARKET
}

\author{
Peter R. Hartley ${ }^{1}$ \\ Princeton University \\ and NBER
}

In this paper I test the hypothesis that expectations of exchange rate movements are formed rationally. To do so, I need, in addition to the hypothesis of rational expectations, a theory of the determinants of exchange rate movements. I shall first consider a very simple "monetary approach" model of exchange rate determination. A serious defect of the model considered in this paper is that it ignores the possibility of a simultaneous determination of the exchange rate along with macroeconomic variables. However, it extends previous models in this genre by attempting to distinguish the effects of changes in expectations on exchange rates from the effects of changes in underlying determining variables apart from expectations. Furthermore, it does this in a context where the assumption of rationality of expectations can be tested.

In the second part of the paper I shall present some results for the U.S. dollar/German Deutschmark and U.S. dollar/Pound Sterling exchange rates in the most recent floating rate period. In the final section I examine a model similar to one studied by Frenkel (1981). However, I am able to test for rationality of expectations where Frenkel could not. I have chosen to emphasize the test of rationality in the paper for two reasons. First the test of rationality, unlike the tests of the restrictions implied by the simple monetary model, does not depend on the validity of the exogeneity assumptions. If we do find a rejection of the cross equation restrictions implied by rationality this is indeed a rejection either of the assumption that expectations are formed rationally 
or that the forward premium differs from the rationally expected depreciation or appreciation by no more than a constant term. Second, I have tested two altemative models of exchange rate determination and while both lead to valid tests of rationality (given our assumption on the forward rate) they do not arise from a single simple model.

\section{Simple Monetary Approach Mode1}

Proponents of the monetary approach to exchange rate determination view the exchange rate as the relative price of two monies. They therefore argue that variables affecting the supply of and demand for two monies will affect the rate of exchange between them. Quite a few studies have tested the monetary approach to exchange rate determination and some of the earlier ones are collected in Frenkel and Johnson (1978).

Since money is a durable asset it has been argued that expectations about the values of variables affecting its future supply of demand ("exogenous" ${ }^{2}$ variables) will be important determinants of current demand. Suppose expectations of future movements in exogenous variables are influenced by current movements in the same exogenous variables. ${ }^{3}$ Movements in the exogenous variables would then affect money supply and demand directly, but would also affect expectations and hence money demand. More significantly, it is most probable that anticipated and unanticipated movements in the exogenous variables will have quite different effects on exchange rates. Frenkel (1979) has suggested that short run movements in exchange rates are dominated by the effect of unanticipated movements in the exogenous variables.

Many previous tests of simple monetary models have included lagged exogenous variables among the explanatory variables. Insofar as the just- 
Ification for including these variables is that they are useful for proxying expectations, an important source of restrictions on the distributed lags has been ignored.

The present study focuses on explaining errors in forecasting exchange rate movements rather than the exchange rate movements themselves. This is one way (also used in Frenkel (1979)) to separate out the effect of anticipated and unanticipated movements in the exogenous variables. Only unanticipated movements in the exogenous variable should lead to unanticipated movements in the exchange rate. Rationality of expectations implies a set of cross-equation restrictions on distributed lags. The conformity of these restrictions with the data provides a test of rationality which I shall implement in this paper.

The statistical theory I shall use derives from a paper by Abel and Mishkin (1979) and has been applied to a study of bond yields by Mishkin (1981).

$$
\text { Let } \begin{aligned}
& \hat{\mathbf{S}}= \text { Tx1 vector of observations on the one period } \\
& \text { percentage change in the exchange rate }
\end{aligned}
$$

and

$$
\begin{aligned}
\Delta= & \text { Txl vector of observations on the errors in } \\
& \text { the forecast of one period exchange rate changes }
\end{aligned}
$$

Hence

$$
\begin{aligned}
\Delta_{t+1} \equiv & \hat{S}_{t+1}-E\left(\hat{S}_{t+1} \mid \phi_{t}\right) \\
\text { where } \phi_{t}= & \begin{array}{l}
\text { information relevant to the pricing of foreign } \\
\text { exchange at time } t+1 \text { available at time } t .
\end{array}
\end{aligned}
$$

Now suppose we have a theory which predicts

$$
\hat{s}_{t+1}=x_{t+1}^{B}+u_{t+1}
$$

where $\mathrm{X}=$ Txk matrix of observations on variables which determine the exchange rate change $\hat{\mathrm{s}}_{t+1}\left(\mathrm{x}_{t+1}\right.$ is observed by agents at time $t+1$ but not before) 


$$
\beta=k x l \text { vector of coefficients. }
$$

Suppose the variables $X$ follow a stochastic process

$$
\mathrm{X}=\mathrm{Zr}+\mathrm{v}
$$

where $\quad Z=T \times l$ matrix of observations on past information

$z_{t}$ (i.e., $z_{t} \in \phi_{t}, t-1,2, \ldots, T$ ) which is useful

for predicting the elements of $X$

$\gamma=$ lxk matrix of coefficients

$v=$ Txk matrix of errors

Now from (1) and (2)

$$
\Delta_{t+1}=\left(x_{t+1}-E\left(x_{t+1} \mid \phi_{t}\right)\right) B+\left[u_{t+1}-E\left(u_{t+1} \mid \phi_{t}\right)\right]
$$

$$
\equiv\left(x_{t+1}-X_{t+1}^{e}\right) \beta+\varepsilon_{t+1}
$$

where I have defined

$$
\begin{aligned}
& x_{t+1}^{e}= \begin{array}{l}
\text { Txk matrix of the one period ahead optimal } \\
\text { forecasts of } x
\end{array} \\
& \varepsilon_{t+1}=\text { Txl vector of errors with } E\left(\varepsilon_{t+1} \mid \phi_{t}\right)=0 .
\end{aligned}
$$

Now if expectations are rational then agents should use the process (3) in forming expectations in (4). In other words we should find

$$
\Delta=(\mathrm{X}-\mathrm{ZY}) \dot{B}+\varepsilon
$$

To test for rationality of expectations we estimate (3) and (5) jointly and test for the quality of the $\gamma$ coefficients in the two sets of equations. An alternative procedure to estimating (3) and (5) jointly would be to first estimate (3) and then use the residuals from that regression in (5). The joint estimation is preferred for several reasons:

(i) The two step procedure does not test whether expectations are optimal linear forecasts given the data on the right hand side of (3). 
(ii) The joint estimation will use information in both (3) and (5) to estimate $\beta$ and $\gamma$ and will deliver more efficient estimates of these parameters.

(iii) It is unlikely that the test statistics derived from the twostep procedure will be consistent since they do not take account of the variance-covariance structure in the regression from which the residuals are derived.

To proceed we need an observable proxy for $E\left(\hat{S}_{t+1} \mid \phi_{t}\right)$, a theory of exchange rate determination (2) and a forecasting equation (3) for the right hand variables in (2).

If traders in the forward foreign exchange market were not risk averse and future prices were known with perfect foresight or were not correlated with the future level of the exchange rate, ${ }^{4}$ we would expect to find

$$
t_{t+1}=E\left(S_{t+1} \mid \phi_{t}\right)
$$

where $t_{t+1}{ }_{t+1}$ is the one period forward rate at time $t$.

To allow for the possibility of risk aversion I shall assume

$$
t_{t+1}^{F}=E\left(s_{t+1} \mid \phi_{t}\right)-a S_{t}
$$

where $a=$ constant

Then

(6) $\quad E\left(s_{t+1} \mid \phi_{t}\right)=\frac{t^{F} t_{1}^{-S} t}{S_{t}}+a$

In Appendix 1 a simple monetary model is used to derive a version of equation (2):

(2)' $\hat{\mathrm{S}}_{t+1}=\hat{\mathrm{M}}_{t+1}-\hat{\mathrm{M}}_{t+1}^{*}-\alpha_{1} \hat{\mathrm{Y}}_{t+1}+\alpha_{2} \hat{\mathrm{Y}}_{t+1}^{*}+\alpha_{3} \Delta\left(i_{t+1}-i_{t+1}^{*}\right)+\xi_{t+1}$ 
where $Y$ and $Y^{*}$ are domestic and foreign real income

$M$ and $M^{*}$ are domestic and foreign money supplies

1 and $1^{*}$ are the domestic and foreign (nominal) interest rates

$\xi_{t+1}$ is a composite error term reflecting deviations from pur-

chasing power parity, as well as random components in

domestic and foreign money demand. $\xi_{t+1}$ can be autocorrelated.

However, the model (2)' is not estimated since the interest parity condition implies that $i_{t+1}-i_{t+1}^{*}$ is related to the expected devaluation of the exchange rate. In Appendix 1, I substitute

$$
i_{t+1}-i_{t+1}^{*}=E_{t+1} \hat{S}_{t+2}-a
$$

into (2)' and then "solve forward" to get an expression for $\hat{\mathrm{s}}_{t+1}$ Involving the expected values of all future money supply and income changes. 5 This expression can also be written ${ }^{6}$

$$
\begin{aligned}
\Delta_{t+1} \equiv & \hat{S}_{t+1}-E_{t} \hat{S}_{t+1}=\sum_{0}^{\infty}\left(\frac{\alpha_{3}}{1+\alpha_{3}}\right)^{i}\left[E_{t+1} \hat{M}_{t+1+i}-E_{t} \hat{M}_{t+1+1}\right]- \\
& \sum_{0}^{\infty}\left(\frac{\alpha_{3}}{1+\alpha_{3}}\right)^{i}\left[E_{t+1} \hat{M}_{t+1+i}^{*}-E_{t} \hat{M}_{t+1+i}^{*}\right]-
\end{aligned}
$$

$$
\begin{aligned}
\alpha_{1} \sum_{0}^{\infty}\left(\frac{\alpha_{3}}{1+\alpha_{3}}\right)^{i}\left[E_{t+1} \hat{Y}_{t+1+i}-E_{t} \hat{Y}_{t+1+1}\right] & +\alpha_{2} \sum_{0}^{\infty}\left(\frac{\alpha_{3}}{1+\alpha_{3}}\right)^{i}\left[E_{t+1} \hat{Y}_{t+1+i}^{*}-\hat{Y}_{t+1+i}^{*}\right] \\
& +\varepsilon_{t+1}
\end{aligned}
$$

Now, we can take the variables $\hat{\mathrm{M}}_{t+1}, \hat{\mathrm{M}}_{t+1}^{*}, \hat{\mathrm{Y}}_{t+1}$ and $\hat{\mathrm{Y}}_{t+1}^{*}$ as the exogenous variables $X$ in (2). As forecasting equation (3) for these variables I use bivariate autoregressions so that: 


$$
\begin{aligned}
& \hat{M}_{t+1}=\gamma_{1}(L) \hat{M}_{t}+\gamma_{2}(L) \hat{Y}_{t}+v_{1 t+1} \\
& \hat{Y}_{t+1}=\gamma_{3}(L) \hat{M}_{t}+\gamma_{4}(L) \hat{Y}_{t}+v_{2 t+1}
\end{aligned}
$$

(3)

$$
\begin{aligned}
& \hat{M}_{t+1}^{*}=\gamma_{1}^{*}(L) \hat{M}_{t}+\gamma_{2}^{*}(L) \hat{Y}_{t}^{*}+v_{3 t+1} \\
& \hat{Y}_{t+1}^{*}=\gamma_{3}^{*}(L) \hat{M}_{t}+\gamma_{4}^{*}(L) \hat{Y}_{t}^{*}+v_{4 t+1}
\end{aligned}
$$

If we use these forecasting equations in (7) it can then be shown ${ }^{7}$ that

$$
\Delta_{t+1}=\left(\hat{M}_{t+1}-E_{t} \hat{M}_{t+1}\right) B_{1}-\left(\hat{M}_{t+1}^{*}-E_{t} \hat{M}_{t+1}^{*}\right) B_{2}
$$

$$
-\left(\hat{Y}_{t+1}-E_{t} \hat{Y}_{t+1}\right) B_{3}+\left(\hat{Y}_{t+1}^{*}-E_{t} \hat{Y}_{t+1}^{*}\right) \beta_{4}+\varepsilon_{t+1}
$$

which is an equation of the form (5). To test for rationality of expectations, we can estimate (3)' and (5)' jointly and require that the $\gamma$ coefficients in equation (5)' equal those in (3)'.

It is important to realize that the $B$ coefficients in (5)' depend on the forecasting parameters $\gamma$ in (3)', as well as elasticities in the underlying money demand functions. In particular, therefore, changes in policy which alter the $\gamma$ parameters in (3)' will alter the $B$ parameters in (5)'. This is a feature of rational expectations models which has been emphasized by Lucas. ${ }^{8}$ In the present context it might make us pessimistic about the chances of getting precise estimates of the $B$ parameters in (5)'. If the forecasting equations (3)' have varied over the sample period and agents have been aware of these changes, then fitting a single time series over the whole period will produce at least two sources of 1mprecision in the estimates of the $\beta$ parameters. First, there will be errors in the right hand side variables in (5)'. Second, the "true" B parameters will have changed over the period. 
The tests of rationality can be strengthened by estimating the system (3)' and (5)' jointly for two exchange rates. In this paper, I have jointly estimated a U.S. dollar/b sterling equation (5)' along with a U.S. dollar/ German DM equation (5)'. If expectations are formed rationally, then the forecast of U.S. variables agents use to preduct the $\$ / \mathrm{t}$ exchange rate should be the same forecast they use to predict the $\$ / D M$ exchange rate. Note, however, that the $E^{\prime} s$ for these two (5)' equations may be correlated. The $\varepsilon^{\prime} s$ represent sources of forecast errors apart form errors in forecasting money and income growths. It is quite likely that the same unaccounted source of error will affect both exchange rates each period. I report one set of estimates which do, and another which do not, allow for this correlation between the $\varepsilon^{\prime} s$.

I have been treating the unanticipated money and income shocks as exogenous with respect to the unanticipated exchange rate error $\Delta$. If monetary policy is varied in response to current innovations in $\varepsilon$ then the $v_{i t}$ 's will be correlated with $\varepsilon_{t}$. This will bias the estimates of the $\beta$ coefficients in (5)'. In fact, it is shown in Abel and Mishkin (1979) that if $\sigma_{v \varepsilon}$ is unknown the $B$ parameters are not identified. Some set of $k$ identifying restrictions on the $k$ elements of $\sigma_{v \varepsilon}$ in (3)' and (5)' is needed to identify the beta parameters. The system (3)' and (5)' cannot be estimated using standard full information maximum likelihood techniques. The covariance matrix must be constrained if we are to get unique estimates for the $\beta$ parameters. In addition, unless the covariance matrix is restricted, In a test of restrictions on the $\beta$ parameters the degrees of freedom of the test statistic could be seriously over-estimated. In all the estimates reported below I restricted $\sigma_{v \varepsilon}=0$ and if this is invalid the estimated $\beta$ coefficients will be biased. 


\section{Estimation of the Simple Monetary Model}

I used M1 money stocks as reported in the IMF International Financial

Statistics. Data on Industrial production were obtained from the same source to serve as proxies for $\mathrm{Y}$ and $\mathrm{Y}^{*}$. The exchange rate data were taken from the Harris Trust and Savings Bank Weekly Bulletin. The month1y observations were taken on the last Friday of each month.

We want a parsimonious set of forecasting equations (3)' to keep the number of estimated parameters to a minimum. We cannot get much guidance from theory on which lags should be included and which excluded from (3)'. I regressed each exogenous variable on 12 of its own lagged values and 12 lagged values of the other exogenous variable from the same country. In all cases this produced white noise residuals. Insignificant variables were then dropped from the regressions.' At each point the residuals were checked to ensure they were still white noise. The forecasting equations arrived at in this way were not altered after the joint estimation had been completed.

Appendix 2 sets out the likelthood function for the joint model (3)' and (5)' for the two exchange rates and discusses the method used to maximize the likelihood function. If we denote the covariance matrix of the error terms in (3)' $\Sigma_{v}$, the covariance matrix of the error terms in (5)' $\Sigma_{\varepsilon}$ and the covariance between $v$ and $\varepsilon \Sigma_{v \varepsilon}$, we can distinguish two situations:

(a) Both $\Sigma_{v}$ and $\Sigma_{\varepsilon}$ are diagonal so that the covariance matrix of the system (3)', (5)' is diagonal.

(b) $\Sigma_{\mathrm{v}}$ and $\Sigma_{\varepsilon}$ are unconstrained although $\Sigma_{\mathrm{v} \varepsilon}$ is constrained to be zero.

In (a) the likelthood function can be maximized by iterative non-linear least squares whereas in (b) an explicit maximum likelihood algorithm is required. Assumption (b) is more general but alas more expensive to implement. The results using the model (a) are set out in Table 1. 
Table 1

Joint Estimation ${ }^{a}$ of (3)' and (5)' with Covariance Structure (a)

Dependent Test ${ }^{\mathrm{b}}$ for

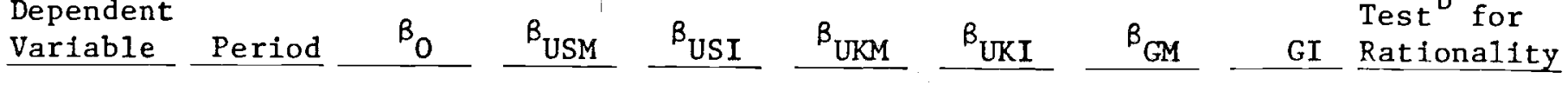
$\begin{array}{lrrrrr}\Delta_{\text {UKUS }} \quad 2 / 72-4 / 79 & .00003 & .348 & .293 & -.130 & .130 \\ & (.0029) & (.373) & (.470) & (.247) & (.143)\end{array}$

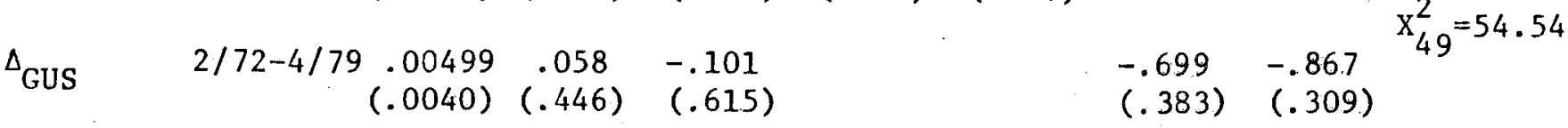

a... Asymptotic standard errors are in,brackets below the coefficients.

Twice the difference in the maximized log likelihood functions.

Most of the beta coefficients are not significantly different from zero. However, as noted above, the beta coefficients predicted by the simple monetary model will be functions not only of the parameters in the money demand function but also the parameters in the forecasting equations for money and income growth. The fact that most of the coefficients are not significantly different from zero cannot be taken as evidence against the simple monetary model. More explicit tests of the simple monetary model will be considered in the next section.

When the covariance structure is generalized to model (b), and the $\log$ likelihood function is explicitly maximized, to reduce the number of parameters to be estimated a more parsimonious parameterization for the forecasting equations is required. Hence the results in Table 2 are not directly comparable with those of Table 1 .

As in Table 1, few of the beta coefficients in Table 2 are significantly different from zero. Furthermore, the coefficients on errors in forecasting U.S. money growth changed sign in moving from Table 1 to Table 2. The most robust beta coefficients appear to be those on German money and income forecasting errors. The cross-equation restrictions implied by rationality were not rejected in the models of either Table 1 or Table 2 . 


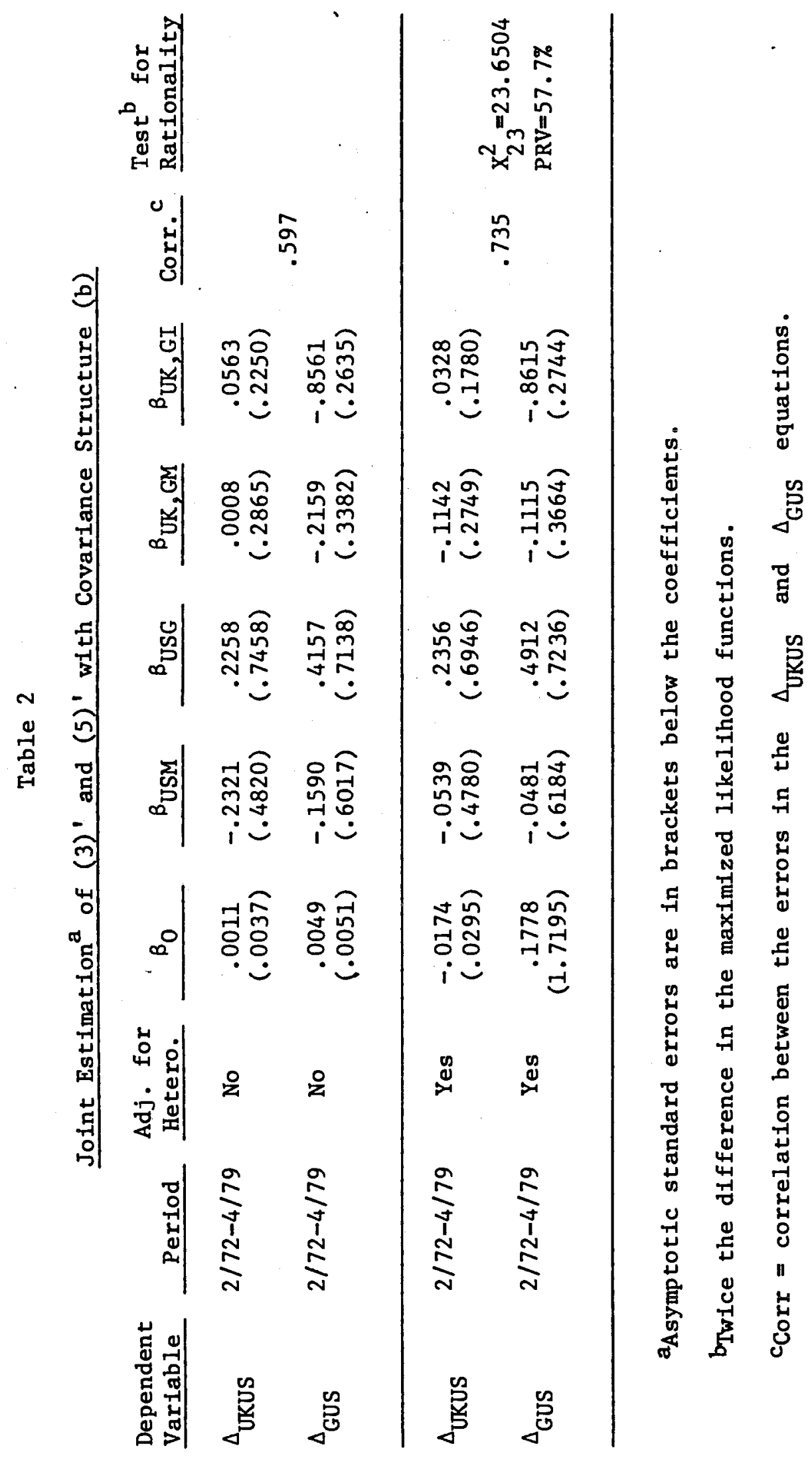


III. Testing the Simple Monetary Model

In Appendix 1, a result from Sargent and Hansen-(1980) is used to express the $B$ coefficients in (5)' in terms of the forecasting parameters $\gamma$ in (3)' and the income elasticities and interest semi-elasticity of demand for money. As long as we restrict the covariance matrix $\Sigma_{v \varepsilon}$ to be zero, the beta coefficients will be identified and the restrictions on those coefficients implied by the simple monetary model can be tested. At the same time, we can recover estimates of the income elasticities and interest semi-elasticity of demand for money which can be compared with the values of these same parameters obtained from estimates of money demand functions.

I attempted to test for the conformity of the simple monetary model with the data using either the real GNP, or bank clearings divided by the wholesale price index, as the income variable. 9 I also tried estimating the model imposing the requirement that $\Sigma_{\mathbf{v}}$ and $\Sigma_{\varepsilon}$ be diagonal or leaving them unconstrained. In all cases I had difficulty getting the algorithms to converge. The problem appeared to be that the likelihood function was maximized for values of the interest semi-elasticity of demand for money $\left(\alpha_{3}\right)$ which were very large so that $\lambda=\frac{\alpha_{3}}{1+\alpha_{3}}$ approached 1 . One example from these "results" is reproduced in Table 3. Note that these parameter estimates are not maximum likelihood estimates as the algorithm was still diverging at these values.

The results must cast considerable doubt on the ability of the simple monetary model to adequately account for the data I examined. However, it should be emphasized again that some of the difficulty might be due to changes over the period in the stochastic processes (3)' governing the evolution of the money and income variables. 
Table 3

\section{Estimation ${ }^{a}$ of the Simple Monetary Model \\ ( $\Sigma$ diagonal)}

\begin{tabular}{|c|c|c|c|c|c|}
\hline \multirow[t]{2}{*}{ Period } & \multirow[t]{2}{*}{$\begin{array}{c}\text { Independent } \\
\text { Variables }\end{array}$} & \multicolumn{3}{|c|}{ Income Elasticities } & \multirow[t]{2}{*}{$\begin{array}{c}\text { Interest } \\
\text { Semi-Elasticity }\end{array}$} \\
\hline & & U.S. & U.K. & $\underline{G}$ & \\
\hline \multirow[t]{2}{*}{$2 / 72-4 / 79$} & M1 growth & -.01482 & -.0832 & .6149 & $21,578.88$ \\
\hline & $\begin{array}{l}\text { Real clearings } \\
\text { growth }\end{array}$ & $(.1757)$ & $(.0717)$ & $(.3655)$ & $(94,754,325.1)$ \\
\hline
\end{tabular}

As a further test of the simple monetary model, I used the term structure of the forward rate to test an alternative implication of the model. I show In Appendix 1 that the error in forecasting the change in the exchange rate over 3 months, if exchange rates are determined in accordance with the simple monetary model of Appendix 1 and expectations are formed rationally, can be written: ${ }^{10}$

$$
\begin{aligned}
\frac{S_{t}-S_{t-3}}{S_{t-3}} & -\frac{t-3 F_{t}-S_{t-3}}{S_{t-3}}=\beta_{0}+\beta_{1} v_{1 t}+\beta_{2} v_{3 t}+\beta_{3} v_{2 t}+\beta_{4} v_{4 t} \\
& +\left[\beta_{1}+\frac{\left(\beta_{1}-1\right)}{\alpha_{3}}\right] v_{1 t-1}+\left[\beta_{2}+\frac{\left(\beta_{2}-1\right)}{\alpha_{3}}\right] v_{3 t-1}+\left[\beta_{3}+\frac{\left(\beta_{3}-1\right)}{\alpha_{3}}\right] v_{2 t-1} \\
& +\left[\beta_{4}+\frac{\left(\beta_{4}-1\right)}{\alpha_{3}}\right] v_{4 t-1}+\left[\beta_{1}+\frac{\left(\beta_{1}-1\right)}{\alpha_{3}} \frac{\left(1+2 \alpha_{3}\right)}{\alpha_{3}}-\frac{\left(\gamma_{11}-\alpha_{1} \gamma_{31}\right)}{\left.\alpha_{3}\right] v_{1 t-2}}\right. \\
& +\left[\beta_{2}+\frac{\left(\beta_{2}-1\right)}{\alpha_{3}} \frac{\left(1+2 \alpha_{3}\right)}{\alpha_{3}}-\frac{\left(\gamma_{11}^{*}-\alpha_{2} \gamma_{31}^{*}\right)}{\alpha_{3}}\right] v_{3 t-2} \\
(8)+\left[\beta_{3}+\frac{\left(\beta_{3}-1\right)}{\alpha_{3}} \frac{\left(1+2 \alpha_{3}\right)}{\alpha_{3}}-\frac{\left(\gamma_{21}-\alpha_{1} \gamma_{41}\right)}{\alpha_{3}}\right] v_{2 t-2} & \left(1+2 \alpha_{3}\right) \\
& +\left[\beta_{4}+\frac{\left(\beta_{4}-1\right)}{\alpha_{3}} \frac{\left(\gamma_{21}^{*}-\alpha_{2} \gamma_{41}^{*}\right)}{\alpha_{3}}\right] v_{4 t-2}+\varepsilon_{t}+\varepsilon_{t-1}+\varepsilon_{t-2}
\end{aligned}
$$

where $\beta_{1}$ and $v_{1 t}$ have exactly the same definition as in equations (3)' and (5)' while $\gamma_{i l}$ is the coefficient of $L^{1}$ in the polynomial $\gamma_{i}$ (L) in 


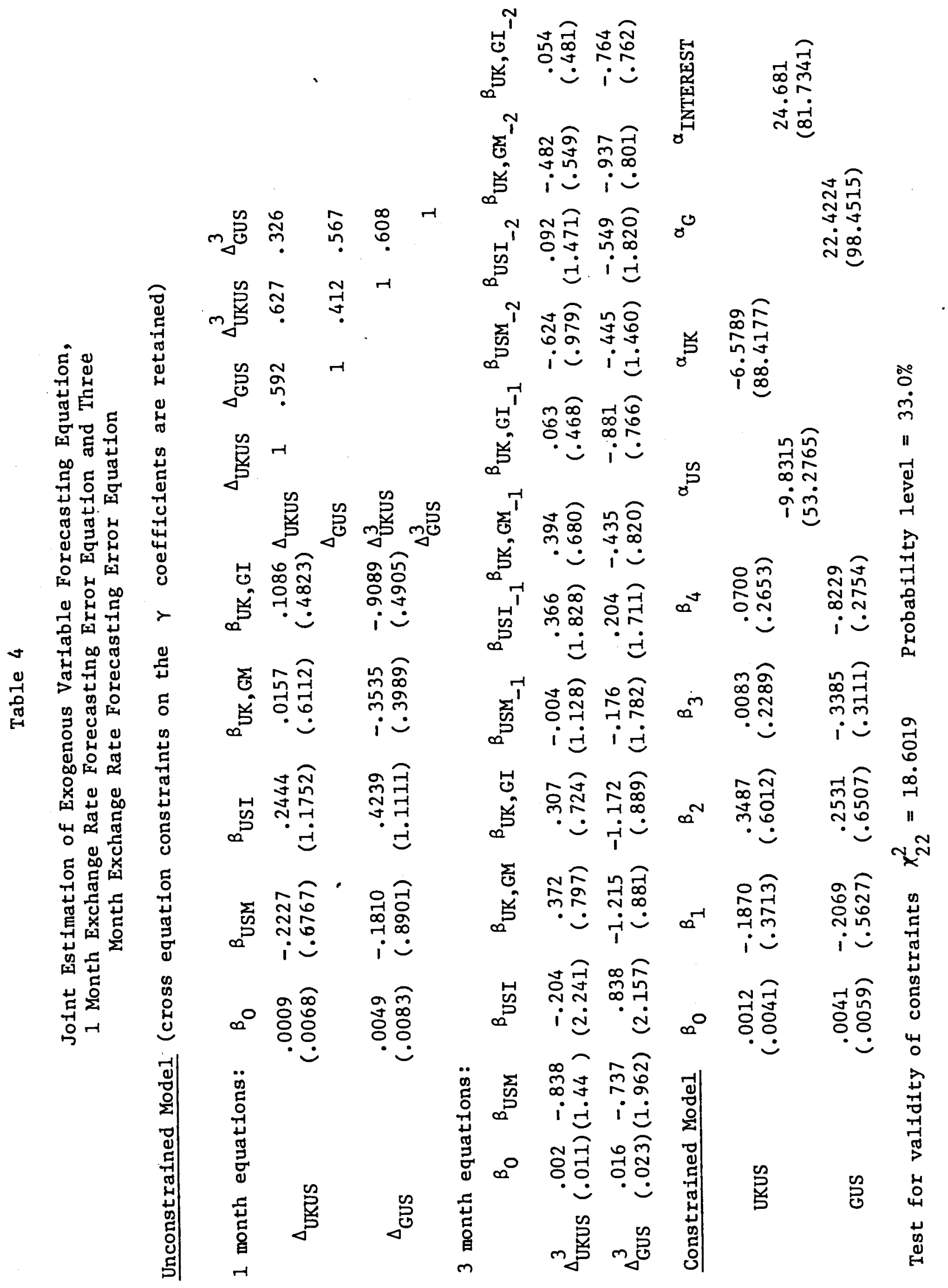


the lag operator in $(3)^{\prime}$ '. The parameters $\alpha_{1}$ and $\alpha_{2}$ are the income elasticity of demand for money in the U.S. and the foreign country (UK or Germany in our case) while $\alpha_{3}$ is the common interest semi-elasticity of the demand for money.

We can get a test of the simple monetary model by estimating (3)', (5)' and (8) jointly and then testing the restrictions on the coefficients in (8). The values of the unrestricted coefficients in (8) are of interest in themselves. If the so-called "overshooting hypothesis" is correct 11 then we might expect to see the coefficients on unanticipated money growth change sign as the lag increases from 1 to three periods in equation (8). The results of jointly estimating the equations (3)', (5)' and (8) are given in Table 4. No adjustments were made for heteroskedasticity. Although the constraints on the coefficients in (8) are not rejected, it is apparent that the beta coefficients in the unconstrained version of (8) are estimated very imprecisely. The results in Table 4 would give one very little confidence that the model (3)', (5)' and (8) is consistent with the data. As far as the overshooting hypothesis is concerned, most of the coefficients in the unconstrained version of (8) follow a pattern

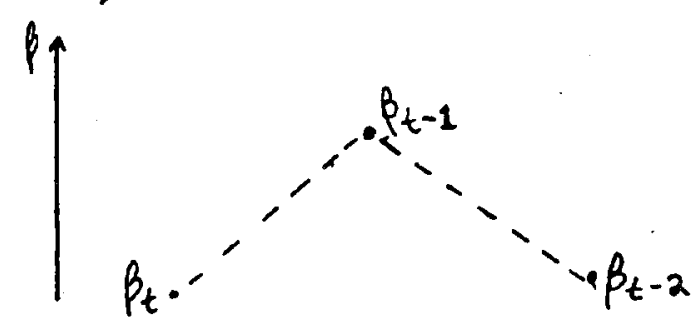

Exceptions to this pattern are the coefficients on U.S. and German income in the German 3-month forecasting error equation. Both of these behave monotonically as a function of the lag but only the coefficients on U.S. income forecasting errors change sign. 
IV. Interest Rate Model

Following Frenkel (1979) I estimated a model

(9)

$$
i_{t+1}=\delta_{1}(\mathrm{~L}) 1_{t}+\delta_{2}(\mathrm{~L}) \hat{M}_{t}+\delta_{3}(\mathrm{~L}) \hat{Y}_{t}+v_{1 t}
$$

$$
i_{t+1}^{*}=\delta_{1}^{*}(L) 1_{t}^{*}+\delta_{2}^{*}(L) \hat{M}_{t}^{*}+\delta_{3}^{*}(L) \hat{Y}_{t}^{*}+v_{2 t}
$$

$$
\Delta_{t+1}=\beta_{0}\left(1_{t+1}-E_{t} 1_{t+1}\right) \beta_{1}+\left(i_{t+1}^{*}-E_{t} i_{t+1}^{*}\right) \beta_{2}+\varepsilon_{t+1}
$$

Although this model has a less rigorous theoretical foundation than the simple monetary model studied in Appendix 1, Frenkel found it was capable of explaining part of the exchange rate forecasting error $\Delta_{t+1}$. He suggested that interest rates and exchange rates might both be affected by the same "news." Further, if both bonds and foreign exchange are traded in efficient financial markets, the time lag between the arrival of the news and its subsequent effect on prices will be similar in the two markets. This begs the question as to the exact nature of the news. It also suggests we should set up a simultaneous equation model where exchange rates and interest rates are both endogenous variables. Frenkel uses instrumental variables to cope with the simultaneity problem. I have ignored it. As above I shall assume that $\varepsilon$ and $v$ in (8) and (10) are uncorrelated. On the other hand, I can test for rationality by testing the validity of the cross equation restrictions on the $\delta$ parameters in (9) and (10). Note that the validity of this test does not depend on the validity of the assumption that $E(\varepsilon, v) \equiv \Sigma_{\varepsilon v}=0$.

In the results reported in Table 5, I used the one-month Eurocurrency rates reported in the Harris Trust and Savings Bank Weekly Bulletin for interest rates. Again $I$ used the rate on the last Friday in each month. 
Date limitations prevented me estimating (9) and (10) over the full period 2/72-4/79. I used maximum likelihood estimation as for the simple monetary model results reported in Table 2.

Table 5

Joint Estimation of (9) and (10)

\begin{tabular}{|c|c|c|c|c|c|c|c|}
\hline $\begin{array}{l}\text { Dependent } \\
\text { Variable }\end{array}$ & Period & $\begin{array}{l}\text { Adj. for } \\
\text { Hetero. }\end{array}$ & $\mathrm{B}_{0}$ & ${ }^{\beta}{ }_{\text {USINT }}$ & ${ }^{B}{ }_{U K, G I N T}$ & Corr. & $\begin{array}{c}\text { Test for } \\
\text { Rationality }\end{array}$ \\
\hline$\Delta_{\text {UKUS }}$ & $10 / 72-4 / 79$ & No & $\begin{array}{l}.1938 \\
(.3875)\end{array}$ & $\begin{array}{c}.7217 \\
(.6250)\end{array}$ & $\begin{array}{l}-.5531 \\
(.1877)\end{array}$ & .543 & \\
\hline${ }^{\Delta}$ GUS & $10 / 72-4 / 79$ & No & $\begin{array}{l}.5554 \\
(.7058)\end{array}$ & $\begin{array}{l}1.2304 \\
(.8254)\end{array}$ & $\begin{array}{l}-.0802 \\
(.5330)\end{array}$ & & \\
\hline$\Delta_{\text {UKUS }}$ & $10 / 72-4 / 79$ & Yes & $\begin{array}{l}-2.2500 \\
(9.9163)\end{array}$ & $\begin{array}{l}.7175 \\
(.4616)\end{array}$ & $\begin{array}{l}-.5399 \\
(.1720)\end{array}$ & & \\
\hline${ }^{\Delta}$ GUS & $10 / 72-4 / 79$ & Yes & $\begin{array}{c}-.6508 \\
(7.7214)\end{array}$ & $\begin{array}{l}1.0428 \\
(.7420)\end{array}$ & $\begin{array}{l}-.1905 \\
(.5472)\end{array}$ & .551 & $\begin{array}{l}x_{34}^{2}=44.9922 \\
P R V=90.15 \%\end{array}$ \\
\hline
\end{tabular}

In contrast to the tests based on the simple monetary model we find some weak evidence against rationality of expectations in Table 4. Also, it is rather interesting to note that although the German equation produced more robust results for the simple monetary model, the UK equation gives more significant beta coefficients when the simple interest rate model is estimated.

V. Conclusion

We have uncovered very little evidence unfavorable to the hypothesis that expectations are formed rationally in the foreign exchange market. 
However, proponents of a simple monetary model of exchange rate determination can find little comfort in the results. There is some evidence that a single simple model may not be satisfactory for explaining all currency movements. This might be related to the different way monetary policy is conducted in different countries. If the monetary authorities followed an interest rate rule then unanticipated innovations in interest rates may provide more relevant information than unanticipated movement in the money stock. The opposite might be the case for a country which followed a money stock growth rate rule. If the authorities did not follow any stable rule over the period examined, then it would be very difficult to test any model of exchange rate determination. This is just another implication of the lucas critique of econometric policy evaluation (Lucas, 1977). Instability in policy over the estimation period could have been a major factor leading to the very imprecise estimates of the $\beta$ parameters found in this paper. 


\section{APPENDIX 1}

\section{A Simple Monetary Mode1}

The model discussed here is a rather simple variant of the models discussed in the monetary approach 1iterature. This has been done since then the model

(i) delivers strong restrictions on the effect of lagged values in the exogenous variables on exchange rate forecast errors 12

and (ii) enables the derivation of testable restrictions on the effect of unanticipated changes in the exogenous variables on forecast errors.

We begin with an equation representing deviations from purchasing power partiy:

(1.1) $\hat{\mathrm{S}}_{t+1}=\hat{\mathrm{P}}_{t+1}-\hat{\mathrm{P}}_{\mathrm{t}+1}^{\star}+\xi_{t+1}$

where a denotes percentage rates of change and $P$ and $P^{*}$ are the domestic and foreign price levels. ${ }^{13}$ Equilibrium in the domestic and foreign money markets require

$(1.2) M / P=L(Y, i)$ and $M^{*} / P^{*}=L^{*}\left(Y^{*}, I^{*}\right)$

where $Y$ and $Y *$ are domestic and foreign real income and 1 and $i *$ are the domestic and foreign (nominal) interest rates. Then from (1.2)

$$
P / P^{*}=[M / L(\cdot)]\left[L^{*}(\cdot) / M^{*}\right]
$$

Now take $e^{14} \quad L=k_{1} Y^{\alpha_{1}} e^{-\alpha_{3} i}$ and $L *=k_{2} Y^{\alpha_{2}} e^{-\alpha_{3}{ }^{i *}}$ 
Then

(1.3) $\hat{P}-\hat{P}^{*}=\hat{M}-\hat{M}^{*}-\alpha_{1} \hat{Y}_{t+1}+\alpha_{2} \hat{Y}_{t+1}+\alpha_{3} \Delta\left(1_{t+1}-_{t+1}^{*}\right)$

and from (1.1) and (1.3)

$$
(1.4) \hat{S}_{t+1}=\hat{M}_{t+1}-\hat{M}_{t+1}^{*}-\alpha_{1} \hat{\mathbb{P}}_{t+1}+\alpha_{2} \hat{\hat{P}}_{t+1}+\alpha_{3} \Delta\left(i_{t+1}-i_{t+1}^{*}\right)+\varepsilon_{t+1}
$$

which is equation (2)' in the text.

Now we impose the interest parity condition. In the absence of transaction costs, arbitrage in assets ensures 15

(1.5) $\frac{t+1 F_{t+2}}{S_{t+1}}=\frac{1+i_{t+1}}{1+i_{t+1}^{\star}}$

where $t+1 F_{t+2}$ is the forward rate at $t+1$ for $t+2$. Expanding $\frac{1}{1+i \star}$ and ignoring squares and higher powers of interest rates we get

$$
\frac{t+1}{S_{t+1}}=1+i_{t+1}-i_{t+1}^{*}
$$

or

(1.6) $i_{t+1}-i_{t+1}^{*}=\frac{t+1}{F_{t+2}-s_{t+1}}=E_{t+1} \hat{s}_{t+2}-a$

from equation (6) in the text. Substitute (1.6) into (1.4)

$$
\hat{\mathrm{S}}_{t+1}=\hat{\mathrm{M}}_{t+1}-\hat{\mathrm{M}}_{\mathrm{t}+1}^{*}-\alpha_{1} \hat{\mathrm{Y}}_{t+1}+\alpha_{2} \hat{\mathrm{Y}}_{\mathrm{t}+1}^{\star}+\alpha_{3} \mathrm{E}_{t+1} \hat{\mathrm{S}}_{t+2}-\alpha_{3} \mathrm{E}_{t} \hat{\mathrm{S}}_{t+1}
$$

$$
+\varepsilon_{t+1}
$$

Take expectations of $(1.7)$ at time $t$ and use $E_{t}\left(E_{t+1} \hat{S}_{t+2}\right)=E_{t} \hat{s}_{t+2}$ to get

$$
E_{t} \hat{S}_{t+1}=E_{t} \hat{M}_{t+1}-E_{t} \hat{M}_{t+1}^{*}-\alpha_{1} E_{t} \hat{Y}_{t+1}+\alpha_{2} E_{t} \hat{Y}_{t+1}^{*}+\alpha_{3} E_{t} \hat{S}_{t+2}
$$

$$
-\alpha_{3} E_{t} \hat{S}_{t+1}
$$


This can be written using the backshift operator as

(1.9) $\left[1+\alpha_{3}-\alpha_{3} B^{-1}\right] E_{t} \hat{s}_{t+1}=E_{t} \hat{M}_{t+1}-E_{t} \hat{M}_{t+1}^{*}-\alpha_{1} E \hat{Y}_{t+1}+\alpha_{2} E_{t} \hat{Y}_{t+1}^{\star}$ But $1+\alpha_{3}-\alpha_{3} B^{-1}=\left(1+\alpha_{3}\right)\left[1-\frac{\alpha_{3}}{1+\alpha_{3}} B^{-1}\right]$ with $\left|\frac{\alpha_{3}}{1+\alpha_{3}}\right|<1$.

Hence

(1.10) $\left(1+\alpha_{3}\right) E_{t} \hat{s}_{t+1}=\sum_{i=0}^{\infty}\left(\frac{\alpha_{3}}{1+\alpha_{3}}\right){ }^{i} E_{t} \hat{M}_{t+1+i}-\sum_{i=0}^{\infty}\left(\frac{\alpha_{3}}{1+\alpha_{3}}\right){ }^{i} E_{t} \hat{M}_{t+1+i}^{*}$

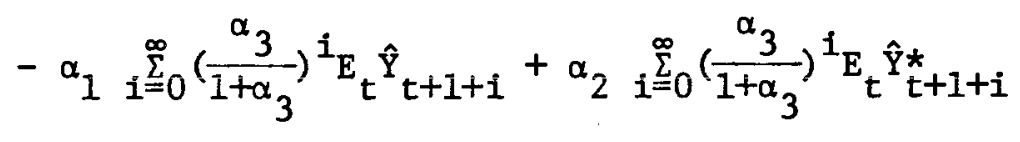

We can lead (1.10) one period to get $E_{t+1} \hat{s}_{t+2}$ and then substitute into (1.7)

$$
\begin{aligned}
& \hat{S}_{t+1}=\hat{M}_{t+1}-\hat{M}_{t+1}^{*}-\alpha_{1} \hat{Y}_{t+1}+\alpha_{2} \hat{Y}_{t+1}^{*}+\frac{\alpha_{3}}{1+\alpha_{3}}\left[\sum_{1=0}^{\infty}\left(\frac{\alpha_{3}}{1+\alpha_{3}}\right){ }^{i_{E}} E_{t+1} \hat{M}_{t+2+i}\right.
\end{aligned}
$$

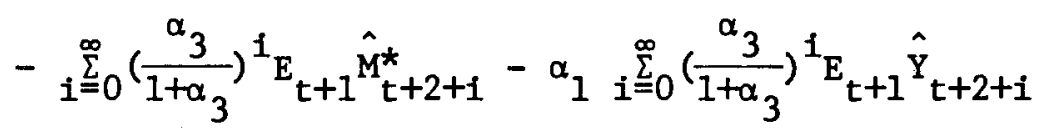

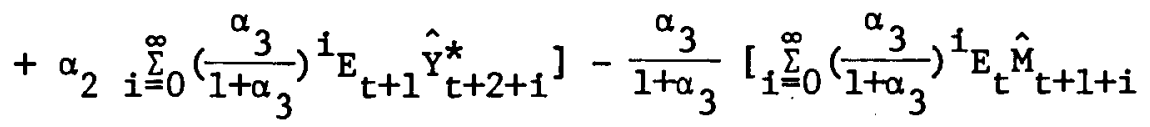

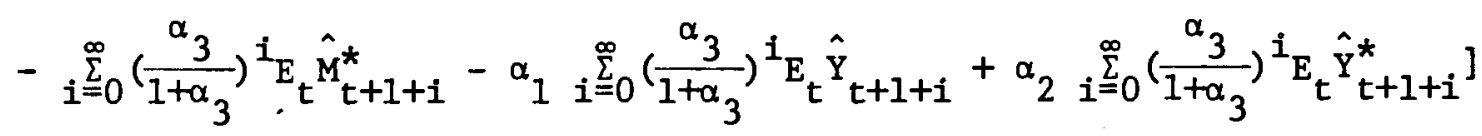

$$
\begin{aligned}
& +\varepsilon_{t+1}
\end{aligned}
$$

From $^{16}(1.11)$

$$
\begin{aligned}
\hat{S}_{t+1} & -E_{t} S_{t+1}=\sum_{0}^{\infty}\left(\frac{\alpha_{3}}{1+\alpha_{3}}\right)^{i}\left[E_{t+1} \hat{M}_{t+1+i}-E_{t} \hat{M}_{t+1+i}\right]-\sum_{0}^{\infty}\left(\frac{\alpha_{3}}{1+\alpha_{3}}\right)^{i}\left[E_{t+1} \hat{M}_{t+1+i}^{*}\right. \\
& \left.\left.-E_{t} \hat{M}_{t+1+1}^{*}\right]-\sum_{0}^{\infty}\left(\frac{\alpha_{3}}{1+\alpha_{3}}\right)_{\left[E_{t+1}\right.} \hat{Y}_{t+1+i}-E_{t} \hat{Y}_{t+1+i}^{*}\right] \\
& +\alpha_{2} \delta_{\delta}^{\infty}\left(\frac{\alpha_{3}}{1+\alpha_{3}}\right)^{i}\left[E_{t+1} \hat{Y}_{t+1+1}^{*}-E_{t} \hat{Y}_{t+1+1]}^{*}+\varepsilon_{t+1}\right.
\end{aligned}
$$


which is equation ( 7 ), in the text.

Now we want to derive equation (5)' in the text. We begin with the forecasting equations (3)'. These can be written using lag operator notation as:

$(1.13)\left[\begin{array}{ll}\gamma_{11}(\mathrm{~L}) & \gamma_{12}(\mathrm{~L}) \\ \gamma_{21}(\mathrm{~L}) & \gamma_{22}(\mathrm{~L})\end{array}\right] \quad\left[\begin{array}{c}\hat{\mathrm{M}}_{\mathrm{t}+1} \\ \hat{\mathrm{Y}}_{\mathrm{t}+1}\end{array}\right]=\left[\begin{array}{l}\mathrm{v}_{1 t+1} \\ \mathrm{v}_{2 t+1}\end{array}\right]$

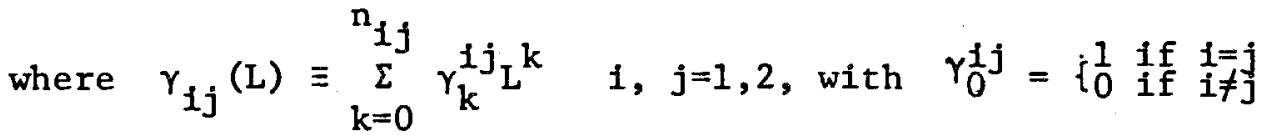

Put $\lambda \equiv \frac{\alpha_{3}}{1+\alpha_{3}}$ and $r=\max _{i j}\left\{n_{i j}\right\} \quad$ and $\quad \gamma_{k}=\left|\begin{array}{cc}\gamma_{11}^{k} & \gamma_{12}^{k} \\ \gamma_{21}^{k} & \gamma_{22}^{k}\end{array}\right| \quad k=1, \ldots, r$.

Then as shown in Sargent and Hansen (1980) we can write

$$
\sum_{i=0}^{\infty} \lambda^{1} E_{t+1} \hat{M}_{t+1+1}=U_{1} \gamma(\lambda)^{-1}\left[I+\sum_{j=1}^{r}\left(\sum_{k=j}^{r} \lambda^{k-j} \gamma_{k}\right) L^{j}\right]\left[\hat{Y}_{t+1}^{t+1}\right]
$$

(1.14) $\left.\sum_{i=0}^{\infty} \lambda^{1} E_{t+1} \hat{Y}_{t+1+i}=U_{2} \gamma(\lambda)^{-1}\left[I+\sum_{j=1}^{r}\left(\sum_{k=j+1}^{r} \lambda^{k-j} \gamma_{k}\right) L^{j}\right] \hat{\hat{Y}}_{t+1}^{\hat{M}_{t+1}}\right]$

where $U_{1}=\left[\begin{array}{ll}1 & 0\end{array}\right]$ and $U_{2}=\left[\begin{array}{ll}0 & 1\end{array}\right]$.

But $\sum_{j=1}^{r} L^{j}\left[\hat{\mathrm{M}}_{t+1}^{t+1}\right]$ is known at time $t$. Therefore,

$\sum_{1=0}^{\infty} \lambda^{1} E_{t} \hat{M}_{t+1+1}=U_{1} \gamma(\lambda)^{-1}\left[E_{E_{t}}^{E_{t} \hat{M}_{t+1}}\right]+U_{1} \gamma(\lambda)^{-1} \sum_{j=1}^{r}\left(\sum_{k=j+1}^{r} \lambda^{k-j} \gamma_{k}\right) L^{j}\left[_{\hat{Y}_{t+1}}^{\hat{M}^{t+1}}\right]$

with a similar expression for $\sum_{1=0}^{\infty} \lambda^{1} E_{t} \hat{\mathrm{Y}}_{\mathrm{y}+1+1}$.

Substitute into $(1.12)$ to get 


$$
S_{t+1}-E_{t} S_{t+1}=\frac{\left[\gamma_{22}(\lambda)+\alpha_{1} \gamma_{21}(\lambda)\right]}{\operatorname{det}(\lambda)}\left(\hat{M}_{t+1}-E_{t} \hat{M}_{t+1}\right)
$$

$$
\begin{aligned}
& -\frac{\left[\gamma_{12}(\lambda)+\alpha_{1} \gamma_{11}^{*}(\lambda)\right]}{\operatorname{det} \gamma(\lambda)}\left(\hat{Y}_{t+1}-E_{t} \hat{Y}_{t+1}\right) \\
& -\frac{\left[\gamma_{22}^{*}(\lambda)+\alpha_{2} \gamma_{11}^{*}(\lambda)\right]}{\operatorname{det} \gamma^{*}(\lambda)}\left(\hat{M}_{t+1}^{*}-E_{t} \hat{M}_{t+1}^{*}\right) \\
& +\frac{\left[\gamma_{12}^{*}(\lambda)+\alpha_{2} \gamma_{11}^{*}(\lambda)\right]}{\operatorname{det} \gamma^{*}(\lambda)}\left(\hat{Y}_{t+1}^{*}-E_{t} \hat{Y}_{t+1}^{*}\right)
\end{aligned}
$$

where $\operatorname{det} \gamma(\lambda)=\gamma_{11}(\lambda) \gamma_{22}(\lambda)-\gamma_{21}(\lambda) \gamma_{12}(\lambda)$

and $\operatorname{det} \gamma^{*}(\lambda)=\gamma_{11}^{*}(\lambda) \gamma_{22}^{*}(\lambda)-\gamma_{21}^{*}(\lambda) \gamma_{12}^{*}(\lambda)$.

Equation (1.16) corresponds to (5)' in the text. The simple monetary model can also be tested using the term structure of the forward rate. We could use expression (1.14) above but I decided to test an alternative expression which is also implied by the simple monetary model.

First observe that

(1.17)

$$
\frac{s_{t}-s_{t-3}}{s_{t-3}}=1 n s_{t}-1 n s_{t-3}=1 n s_{t}-1 n s_{t-1}+1 n s_{t-1}-1 n s_{t-2}+1 n s_{t-2}-1 n s_{t-3}
$$

$$
\begin{aligned}
=s_{t}+s_{t-1} & +S_{t-2} \\
\text { So } \frac{s_{t}-s_{t-3}}{S_{t-3}}-\frac{t-3 F_{t}-S_{t-3}}{S_{t-3}}=\left(\hat{S}_{t}-E_{t-3} \hat{S}_{t}\right) & +\left(\hat{S}_{t-1}-E_{t-3} \hat{S}_{t-1}\right) \\
& +\left(\hat{S}_{t-2}-E_{t-3} \hat{S}_{t-2}\right)
\end{aligned}
$$

Now use (1.12) together with the forecasting equations as in (3)' in the text 


$$
\begin{aligned}
& \hat{\mathrm{M}}_{t+1}=\gamma_{1}(\mathrm{~L}) \hat{\mathrm{M}}_{t}+\gamma_{2}(\mathrm{~L}) \hat{\mathrm{Y}}_{t}+v_{1 t-1} \\
& \hat{\mathrm{Y}}_{t+1}=\gamma_{3}(\mathrm{~L}) \hat{\mathrm{M}}_{t}+\gamma_{4}(\mathrm{~L}) \hat{\mathrm{Y}}_{t}+v_{2 t+1}
\end{aligned}
$$

(1.18)

$$
\begin{aligned}
& \hat{M_{t+1}^{*}}=\gamma_{1}^{*}(L) \hat{M}_{t}^{*}+\gamma_{2}^{*}(L) \hat{Y}_{t}^{*}+v_{3 t+1} \\
& \hat{Y}_{t+1}^{*}=\gamma_{3}^{*}(L) \hat{M}_{t}^{*}+\gamma_{4}^{*}(L) \hat{Y}_{t}^{*}+v_{4 t+1}
\end{aligned}
$$

where $\gamma_{i}(L) \sum \sum_{j=1}^{n} \gamma_{i j} L^{j}, \quad \gamma_{i}^{*}(L) \equiv \sum_{j=1}^{n} \gamma_{i j}^{*} L^{j} \quad i=1,2,3,4$

Then $\hat{s}_{t}-E_{t-3} \hat{S}_{t}$, for example will contain terms like

$$
\hat{M}_{t}-E_{t-3} \hat{M}_{t}, E_{t} \hat{M}_{t+1}-E_{t-3} \hat{M}_{t+1}, \ldots
$$

and $E_{t-1} \hat{M}_{t}-E_{t-3} \hat{M}_{t}, E_{t-1} \hat{M}_{t+1}-E_{t-3} \hat{M}_{t+1}, \cdots$

Now use (1.15) to evaluate these. For example,

$$
\begin{aligned}
\hat{M}_{t}-E_{t-3} \hat{M}_{t} & =\left[\gamma_{11}^{2}+\gamma_{12}+\gamma_{21} \gamma_{31}\right] v_{1 t-2}+\left[\gamma_{22}+\left(\gamma_{11}+\gamma_{41}\right) \gamma_{21}\right] v_{2 t-2} \\
& +\gamma_{11} v_{1 t-1}+\gamma_{21} v_{2 t-1}+v_{1 t}
\end{aligned}
$$

and

$$
\begin{aligned}
E_{t-1} \hat{M}_{t}-E_{t-3} \hat{M}_{t} & =\left[\gamma_{11}^{2}+\gamma_{12}+\gamma_{21} \gamma_{31}\right] v_{1 t-2}+\left[\gamma_{22}+\left(\gamma_{11}+\gamma_{41}\right) \gamma_{21}\right] v_{2 t-2} \\
& +\gamma_{11} v_{1 t-1}+\gamma_{21} v_{2 t-1}
\end{aligned}
$$

Put $E_{t} \hat{M}_{t+i}-E_{t-1} \hat{M}_{t+i} \equiv \xi_{11} v_{1 t}+\zeta_{1 i} v_{2 t}$

$$
E_{t} \hat{Y}_{t+i}-E_{t-1} \hat{Y}_{t+i} \equiv \xi_{2 i} v_{1 t}+\zeta_{2 i} v_{2 t}
$$


and $\beta_{1} \equiv \sum_{0}^{\infty}\left(\frac{\alpha_{3}}{1+\alpha_{3}}\right)^{1}\left(\xi_{11}-\alpha_{1} \xi_{21}\right)$

$$
\beta_{3} \equiv \sum_{0}^{\infty}\left(\frac{\alpha_{3}}{1+\alpha_{3}}\right)^{1}\left(\zeta_{11}-\alpha_{1} \zeta_{21}\right)
$$

Define $\zeta^{*}, \zeta^{*}$ and $\beta_{2}, \beta_{4}$ analogously for the foreign variables.

Then it can be shown that

$$
\begin{aligned}
\hat{S}_{t} & -E_{t-3} \hat{s}_{t}=\beta_{1} v_{1 t}+\beta_{2} v_{3 t}+\beta_{3} v_{2 t}+\beta_{4} v_{4 t}+\frac{1}{\alpha_{3}}\left[\left(\beta_{1}-1\right) v_{1 t-1}\right. \\
& \left.+\left(\beta_{2}-1\right) v_{3 t-1}+\left(\beta_{3}-1\right) v_{2 t-1}+\left(\beta_{4}-1\right) v_{2 t-1}\right] \\
& +\left(\frac{1+\alpha_{3}}{\alpha_{3}^{2}}\right)\left\{\left[\beta_{1}-1-\frac{\alpha_{3}}{1+\alpha_{3}}\left(\gamma_{11}-\alpha_{1} \gamma_{31}\right)\right] v_{1 t-2}+\left[\beta_{2}-1-\frac{\alpha_{3}}{1+\alpha_{3}}\left(\gamma_{11}^{*}-\alpha_{2} \gamma_{31}^{*}\right)\right] v_{3 t-2}\right. \\
& \left.+\left[\beta_{3}-1-\frac{\alpha_{3}}{1+\alpha_{3}}\left(\gamma_{21}-\alpha_{1} \gamma_{41}\right)\right] v_{2 t-2}+\left[\beta_{4}-1-\frac{\alpha_{3}}{1+\alpha_{3}}\left(\gamma_{21}^{*}-\alpha_{2} \gamma_{41}^{*}\right)\right] v_{4 t-2}\right\}+\varepsilon_{t}
\end{aligned}
$$

Similarly,

$$
\begin{aligned}
\hat{s}_{t-1} & -E_{t-3} \hat{S}_{t-1}=\beta_{1} v_{1 t-1}+\beta_{2} v_{3 t-1}+\beta_{3} v_{2 t-1}+\beta_{4} v_{4 t-1} \\
& +\frac{1}{\alpha_{3}}\left[\left(\beta_{1}-1\right) v_{1 t-2}+\left(\beta_{2}-1\right) v_{3 t-2}+\left(\beta_{3}-1\right) v_{2 t-2}+\left(\beta_{4}-1\right) v_{4 t-2}\right]+\varepsilon_{t-2}
\end{aligned}
$$

and

$$
\hat{S}_{t-2}-E_{t-3} \hat{S}_{t-2}=\beta_{1} v_{1 t-2}+\beta_{2} v_{3 t-2}+\beta_{3} v_{2 t-2}+\beta_{4} v_{4 t-2}+\varepsilon_{t-2}
$$

Substitute into (1.17). The simple monetary model predicts that $\frac{S_{t}-S_{t-3}}{S_{t-3}}-\frac{t-3 F_{t}-S_{t-3}}{S_{t-3}}$ will be a moving average of the one-period forecasting errors $\quad v_{i t-j} \begin{aligned} & i=1,2,3,4 \\ & j=0,1,2\end{aligned}$ 
Furthermore, if we jointly estimate

$$
\begin{aligned}
& \frac{S_{t}-S_{t-1}}{S_{t-1}}- \frac{t-1 F_{t}-S_{t-1}}{S_{t-1}}=\beta_{1} v_{1 t}+\beta_{2} v_{3 t}+\beta_{3} v_{2 t}+\beta_{4} v_{4 t}+\varepsilon_{t} \\
& \text { and } \frac{S_{t}-S_{t-3}}{S_{t-3}}-\frac{t-3 F_{t}-S_{t-3}}{S_{t-3}}=\beta_{1} v_{1 t}+\beta_{2} v_{3 t}+\beta_{3} v_{2 t}+\beta_{4} v_{4 t}+\left[\beta_{1}+\frac{\beta_{1}-1}{\left.\alpha_{3}\right] v_{1 t-1}}\right. \\
&+\left[\beta_{2}+\frac{\beta_{2}-1}{\alpha_{3}}\right] v_{3 t-1}+\left[\beta_{3}+\frac{\beta_{3}-1}{\alpha_{3}}\right] v_{2 t-1}+\left[\beta_{4}+\frac{\beta_{4}-1}{\alpha_{3}}\right] v_{4 t-1} \\
&+\left[\beta_{1}+\frac{\beta_{1}-1}{\alpha_{3}} \frac{1+2 \alpha_{3}}{\alpha_{3}}-\frac{\left(\gamma_{11}-\alpha_{1} \gamma_{31}\right)}{\alpha_{3}}\right] v_{1 t-2}+\left[\beta_{2}+\frac{\beta_{2}-1}{\alpha_{3}} \frac{1+2 \alpha_{3}}{\alpha_{3}}\right. \\
&\left.-\frac{\left(\gamma_{11}^{*}-\alpha_{2} \gamma_{31}^{*}\right)}{\alpha_{3}}\right] v_{3 t-2}+\left[\beta_{3}+\frac{\beta_{3}-1}{\alpha_{3}} \frac{1+2 \alpha_{3}}{\alpha_{3}}-\frac{\left(\gamma_{21}-\alpha_{1} \gamma_{41}\right)}{\alpha_{3}}\right] v_{2 t-2} \\
&+\left[\beta_{4}+\frac{\beta_{4}-1}{\alpha_{3}} \frac{1+2 \alpha_{3}}{\alpha_{3}}-\frac{\left(\gamma_{21}^{*}-\alpha_{2} \gamma_{41}^{*}\right)}{\alpha_{3}}\right] v_{4 t-2}+\varepsilon_{t}+\varepsilon_{t-1}+\varepsilon_{t-2}
\end{aligned}
$$

the restrictions on the beta coefficients implied by the simple monetary model can be tested. As above, estimates of the elasticity parameters in the money demand functions will also be obtained and these can be compared with estimates of these same parameters which have been obtained by other methods. 


\section{APPENDIX 2 \\ The Likelihood Function for the Model (3), (5)}

To simplify the exposition I will use the notation of equations (3) and (5) in the text rather than the more explicit but more cumbersome notation of (3)' and (5)'.

We want the likelihood function for the simultaneous system

$$
\begin{aligned}
& \mathrm{X}=\mathrm{z} \gamma+\mathrm{v} \\
& \Delta=(\mathrm{X}-\mathrm{Z} \gamma) \beta+\varepsilon
\end{aligned}
$$

Let $\left(\mathrm{x}_{1 t}, \ldots, \mathrm{x}_{k t}, \Delta_{t}\right)$ be the $1 \mathrm{x}(\mathrm{k}+2)$ vector of observations on the endogenous variables at time $t$ and let $\left(z_{1 t}, \ldots, z_{\ell t}\right)$ be the $1 \times \ell$ vector of observations on the' exogenous variables at time $t$. Then the system can be written

$$
\left(x_{1 t}, \ldots, x_{k t}, \Delta_{t}\right) B+\left(z_{1 t}, \ldots, z_{l t}\right) \Gamma=\left(v_{t}, \varepsilon_{t}\right)
$$

where

$$
\begin{aligned}
& B=\left(\begin{array}{c:c}
I_{k} & -\beta \\
\hdashline 0 & I_{2} \\
& \\
\hdashline=(\gamma & \gamma \beta
\end{array}\right)
\end{aligned}
$$

Since $\operatorname{det} B=1$ we can write the $\log$ likelihood function ${ }^{17}$

$$
\begin{aligned}
& L^{*}=-\frac{1}{2} n(k+1) \log 2 \pi-\frac{n}{2} \operatorname{logdet} \Sigma-\frac{1}{2} \sum_{t=1}^{n}\left(v_{t} \varepsilon_{t}\right) \Sigma^{-1}\left(_{\varepsilon_{t}^{\prime}}^{v_{t}^{\prime}}\right) \text { where } \\
& \begin{array}{lll}
\Sigma_{v} & 0 \\
\hdashline 0 \quad & \Sigma_{\varepsilon}
\end{array}
\end{aligned}
$$


If $\Sigma_{v}$ and $\Sigma_{\varepsilon}$ are diagonal the log likelihood can be maximized by dividing each of the equations by the estimated variance of the residual of that equation and then using non-linear least squares to obtain the parameter estimates $\gamma$ and $B$.

In the more general case where $\Sigma_{\mathrm{v}}$ and $\Sigma_{\varepsilon}$ are unrestricted I used an algorithm specified in a paper by Berndt, Hall, Hall and Hausman (1974).

In both cases, I corrected the residuals for heteroskedasticity using the time trend procedure outlined by Glesjer and discussed in Johnston (1963). Initial parameter estimates were obtained and the absolute values of the residuals were then regressed on a constant and a time trend to get two parameters $\beta_{10}$ and $\beta_{11}$ for each equation 1 . The data of equation 1 were then corrected by dividing by the square root of $\beta_{10}+\beta_{11}$. time. Parameter estimates using the corrected data were then obtained. While this procedure is satisfactory when $\Sigma_{\mathbf{v}}$ and $\Sigma_{\varepsilon}$ are diagonal, it would have been preferable in the more general case to have included time trend terms in $\Sigma_{\mathbf{v}}$ and $\Sigma_{\varepsilon}$. However, this would have greatly increased the number of parameters to be estimated. Results for both the unadjusted and adjusted data are reported when $\Sigma_{v}$ and $\Sigma_{\varepsilon}$ are not constrained to be diagonal. 


\section{Footnotes}

1. I would particularly like to thank Frederick S. Mishkin for many valuable discussions and suggestions. I would also like to thank Jacob A. Frenkel and Robert J. Hodrick for their comments. Financial support from the Lilly Endowment Fund, the University of Chicago, and Princeton University is gratefully acknowledged.

2. I shall use the term "exogenous" for these determining variables for ease of exposition. Some of them might in fact be simultaneously determined with money supply and/or demand. This shall be discussed further below.

3. This will be true, for example, if the evolution of these exogenous variables can be explained by a stable low order autoregression and agents are aware of this fact and form expectations rationally.

4. See Frenkel and Razin (1980).

5. This was also done in Mussa (1978) and Bilson (1978).

6. $\varepsilon_{t+1}=\xi_{t+1}-E_{t} \xi_{t+1}$.

7. See Appendix 1.

8. See Lucas (1977).

9. Bank clearings and the wholesale price indices were obtained from the International Financial Statistics. I used this variable to capture the transactions demand for money.

10. Note that the theory implies the error term in equation (8) will be a moving average. This fact has been ignored in the estimation and will lead to inefficient estimates of the parameters of the model.

11. See Dornbusch (1976) for example. 
12. If, for example, partial adjustment parameters were appended to the present model, a far wider range of estimated lagged effects would be consistent with the model. However, I would consider that a weakness and not a strength of the extended model. If one is to postulate a model with lagged adjustments, it would be preferable to have a theory explaining the source of the lags so that one could get restrictions on the adjustinent. parameters more open to refutation.

13. Frenkel (1978) discusses the use of the relevant price index to use here. To the extent that purchasing power parity pertains to traded goods only, (1.1) would also contain terms involving the relative price of traded to non-traded goods.

14. The functional forms proposed here for the money demand functions are common in monetary economics and exchange rate literature.

15. Equation (1.5) has been tested previously in quite a few studies and appears to hold up reasonably well (see for example Frenkel and Levich, 1975, 1977 and Levich L978, 1979).

16. Note that if $\varepsilon$ is autocorrelated so $\varepsilon_{t+1}=\alpha(L) \varepsilon_{t}+\nu_{t+1}$ then $E_{t} \varepsilon_{t+1}=\alpha(L) \varepsilon_{t}$ and $\varepsilon_{t+1}-E_{t} \varepsilon_{t+1}=E_{t+1}-\alpha(L) \varepsilon_{t}=\nu_{t+1}$ and we will still get an uncorrelated error term in (1.12).

17. See for example Schinidt (1976), p. 216. 


\section{REFERENCES}

Abel, Andrew and Mishkin, Frederic S. 1979. On the econometric testing of rationality and market efficiency. University of Chicago, Center for Mathematical Studies in Business and Economics, Report 7933. Mimeographed.

Berndt, E. K., Hall, B. H., Hall, R. E., and Hausman, J. A. 1974. Estimation and inference in nonlinear structural models. Annals of Economic and Social Measurement 3/4: 653-665.

Bilson, John F. O. 1978. Rational expectations and the exchange rate. In Frenkel and Johnson. (1978).

Dornbusch, Rudiger. 1976. Exchange rate dynamics. Journal of Political Economy 84: 1161-1176.

Frenkel, Jacob A. 1978. A monetary approach to the exchange rate: Doctrinal aspects and empirical evidence. In Frenkel and Johnson (1978). - 1981. Flexible exchange rates, prices and the role of

'news': Lessons from the 1970s. Journal of Political Economy 89: $665-705$.

Frenkel, Jacob A. and Johnson, Harry G., eds. 1978. The economics of exchange rates. Reading: Addison Wesley.

Frenkel, Jacob A. and Levich, Richard M. 1975. Covered interest arbitrage: Unexploited profits? Journal of Political Economy 83: 325-38. - 1977. Transaction costs and interest arbitrage: Tranquil versus turbulent periods. Journal of Political Economy 85: 1207-24. Frenkel, Jacob A. and Razin, Assaf. 1980. Stochastic prices and tests of efficiency of foreign exchange markets. Economics Letters 6: 165-170. 
Hansen, Lars P. and Sargent, Thomas J. 1980. Formulating and estimating dynamic linear rational expectations models. Journal of Economic Dynamics and Control 2: 7-46.

Levich, Richard H. 1978. Tests of forecasting models and market efficiency in the international money market. In Frenkel and Johnson (1978). - 1979. On the efficiency of markets for foreign exchange. In Dornbusch, R. and Frenkel, J.A., eds., International Economic Policy: Theory and Evidence. Baltimore: Johns Hopkins University Press. Lucas, Robert E. Jr. 1976. Econometric policy evaluation: A critique. In Brunner, K. and Meltzer, A., eds., The Phillips Curve and the Labor Market. Carnegie-Rochester Conferences in Public Policy, vol. 1. Supplementary series to the Journal of Monetary Economics.

Mishkin, Frederic S. 1980. Monetary policy and long-term interest rates: An efficient markets approach. Journal of Monetary Economics 7: 29-55. Mussa, Michael. 1978. The exchange rate, the balance of payments, and monetary and fiscal policy under a regime of controlled floating. In Frenkel and Johnson (1978). Schmidt, Peter. 1976. Econometrics. New York: M. Decker, Inc. 